https://doi.org/10.52449/1857-4114.2021.37-1.06

CZU: 572.7:796.333-055.2

\title{
ANALYSIS ON SPECIFIC MORFOLOGIC ADAPTATION IN THE GAME OF RUGBY IN 7 - FEMININE, SENIOR LEVEL
}

Lepciuc Gabriela ${ }^{1}$, ORCID: 0000-0003-3904-2446

Dorgan Viorel', ORCID: 0000-0002-4649-4734

Popescu Veronica ${ }^{3}$, ORCID: 0000-0002-4545-9849

${ }^{1}$ High School Radeni, Iasi, Romania

${ }^{2}$ State University of Physical Education and Sport, Chisinau, Republic of Moldova

3 „Alexandru Ioan Cuza” University, Iasi, Romania

\begin{abstract}
With the transition of rugby in 7 as an Olympic sport, performance standards have increased, the game becoming much faster and well structured, which also brings major changes in terms of the morphological profile of the player. The aim of this research is to achieve the morphological profile of rugby players from the first domestic league, and then the results to be compared with those of the players of professional leagues from countries with a tradition in the sport. The study took place in the pre-competition stage, on 24 professional rugby players, all active in the first league of the domestic championship in Romania and Ukraine respectively. The group represented by the team SC Politehnica Iasi, aged between 18-29 years-old and lot B components of the team from Ukraine, aged 18-31 years-old, both teams having rugby experience between 4-18 years-old. The research methods used in the study were: literature analysis, observation, pedagogical experiment, statistical, graphic representation method. The tests applied were: height, body mass, muscle mass, muscle fat tissue and mobility of the spine. The results of the analysis on compartments help to confirm the hypothesis, since following the study started, the players of the forwards compartment fall between the optimal values of the players of lot B, the back compartment recording values close to the optimal ones.
\end{abstract}

Keywords: rugby, morphological adaptation, game, tests.

\section{Introduction}

Rugby in 7 is a spectacular branch of rugby. It is a sport characterized by the speed of execution, skill and the ability of the player to make decisions very quickly. The number of players and the time of play make the difference between VII and XV [7]. These differences also make their mark on the player's profile.

Being a game played on a field of the same size as rugby in the $\mathrm{XV}$, the ephor submitted by the players to cover all the spaces during the match is comparatively much higher $[6,7]$.

Anthropometric, physical and motor requirements are considered traditional key criteria in the selection of the rugby player. Each of the rugby-specific compartments (forwards and backs) have physical requirements, skills and special tasks to perform within the team.

As the level of play improves, fat-free mass, height and mass increases, and body fat percentage decreases. Many studies have reported significant differences between competitive levels (amateur and elite) $[4,9]$.

In general, the results of these studies indicate that the selection of players in highlevel teams may be based in part on the size and physical capabilities of athletes [8]. Apparently, players who are selected in elite 
teams can increase their lean body mass due to larger and more specific training.

Some research has shown that elite rugby players from Australia and Canada, top teams in the Women's World Series, tend to be taller $(166-170 \mathrm{~cm})$ and heavier $(69-73 \mathrm{~kg})(5,27$, $77,79)$ than players from Spain, France and Japan (height, 164 - $167 \mathrm{~cm}$; body mass 60 $68 \mathrm{~kg})[8,9]$.

The morphological differences in rugby in 7 between the forwards package and the backs are small compared to the game of $\mathrm{XV}$ players.

Only two studies compared the differences in position in anthropometry in seven women's rugby. While a study has shown that the forwards package is moderately higher and heavier [1], another study showed that there is no difference in height or body fat, with only obvious differences in body mass and muscle mass [8].

The body fat of elite rugby players ranges from about 8 to $17 \%$ [4]. Body fat does not contribute to the generation of muscle strength and therefore excessive amounts of body fat will affect sprinting ability.

The body composition of the players is similar to that of rugby players in 15 , only in the backs compartment, with a low percentage of fat tissue, allowing for higher speed and anaerobic strength.

Body composition is a very important factor in the development of an athlete. Depending on muscle mass and percentage of fat tissue, players may or may not reach the performance they have set.

Unlike other sports where muscles are predominantly required by a certain part of the body, in rugby all muscle groups are used more or less, the harmonious physical development of the player is important.

Rugby players are known in the world of sport for a very well developed neck muscle. Well, at the level of rugby in the women's and men's $7 \mathrm{~s}$, this part of the body is much more used by forward players.
At the muscular level, a rugby player in 7 has a well-developed and structured muscle, similar to that of an athlete.

Mobility, speed, skill and reaction are features that define the game in 7. In 15-way rugby, spaces become restricted which makes contact phases the key to the game. In order to gain ground, there are the players of the forward deck in particular who use their maximum force. This is where the differences in muscle level start.

Due to the fact that this game is very fast and the contact phases have a considerable impact on the body, great attention should be paid to the biomechanical aspects of the different phases of the game, as well as the development in equal proportions of muscle mass.

Joint mobility and muscle flexibility are of major importance to any person, especially when it comes to athletes. Good mobility allows players to achieve large, precise and fast movements, very important factors in the game of rugby.

The development of mobility is beneficial not only in achieving movements on maximum amplitude, helping to prevent injuries, a faster recovery after exertion, as well as to streamline movements and increase performance at the same time.

In order to carry out the research, we assume that the women's rugby team "C.S. Politechnica" Iaşi, a team that is in the first value echelon, being multiple national champion, falls between the optimal parameters in terms of specific morphological aspects.

\section{Methodology and organisation of research}

The study took place in the precompetition stage, on 24 professional rugby players, all active in the first league of the domestic championship in Romania and Ukraine respectively, being components of two distinct lots, delineated as follows:

Lot A- It is represented by 12 players, all of which are components of the women's 
rugby team within the Sports Club "Politehnica" Iasi.

The players range in age from 18 to 29 , all with rugby experience between 4 and 18 years. The team is active in the first intern league, for the last 4 years being the national champion of Romania.

Lot B- It consists of 12 players, components of the Ukrainian rugby team. The players are between the ages of 18 and 31, with rugby experience between 4 and 18 years, playing for the national team for more than 3 years.

The aim of this research is to achieve the morphological profile of rugby players from the first intern league, and then the results to be compared with those of the players of professional leagues from countries with a tradition in the sport.

Due to the fact that the ace of the branch of rugby does not depend on promotionand in-depth studies on players, we are trying through this study to achieve the ideal somatic profile of a rugby player in seven.

In the study we set the following objectives:

- Selecting rugby players and dividing them into groups ;

- Somatoscopic and somatometric evaluation of rugby players;

- Statistical interpretation of the data we will obtain.

The research methods used in the study were: the analysis of the specialized literature, the method of observation, pedagogical experiment, statistical and graphic method.

In order to be able to assess the actual or accidental nature of the variations in the values of the mean, the differences in the indices studied in the experimental models, it was necessary to calculate, for each case, the significance test.

The tests carried out on the sports were carried out at the beginning of the competition season, all of which were carried out with the agreement of the coaches and officials of the two teams.

The tests applied were: waist, body mass, muscle mass, body fat and spinal mobility. At the beginning of the season, all sportswomen used for this study are required to carry out a set of specialized medical investigations. These investigations are currently being carried out within the is Medical Center Prevention in Iasi, for sportswomen in lot A, respectively at the National Institute of Sports Medicine in Bucharest, in the case of sports women in lot B.

Body mass - was measured using a precision electronic scale. Even though the mass was recorded at the decigram level, the results were rounded out to eliminate errors caused by differences in metabolism between subjects.

Height - represents the distance between the vertex and the plant plane and has been evaluated using the taliometer. The subject analyzed is in orthostatism, with the lower limbs in extension and the right spine. The heels, the interfesier ditch and the column next to the shoulder blades touch the taliometer rod. The chin is lowered towards the chest so that the upper edge of the external auditory conduction and the external angle of the eye are on the same horizontal line.

Muscle mass along side muscle fat tissue were measured using a body composition monitor.

Mobility of the lumbar spine was measured using a flexometer.

Results and discussions 
Table 1. Test results of the C.S Politehnica Iasi

\begin{tabular}{|c|c|c|c|c|c|}
\hline No. & $\begin{array}{c}\text { Name /first } \\
\text { name }\end{array}$ & Positions & Height & $\begin{array}{c}\text { Weight } \\
\text { (kg) }\end{array}$ & $\begin{array}{c}\text { Spinal } \\
\text { mobility (cm) }\end{array}$ \\
\hline 1 & A.A. & Wing & 159,00 & 54,60 & 25,50 \\
\hline 2 & G.G & Hooker & 171,00 & 55,10 & 20,40 \\
\hline 3 & J.L & Props & 167,00 & 65,10 & 15.30 \\
\hline 4 & L.G & Scrum-half & 163,00 & 55,80 & 25,00 \\
\hline 5 & N.A & Center & 165,00 & 53,40 & 20,00 \\
\hline 6 & B.G & Fly-half & 162,50 & 57,00 & 14,00 \\
\hline 7 & S.A & Center & 160,00 & 57,30 & 7,70 \\
\hline 8 & R.S & Scrum-half & 158,00 & 56,40 & 18,00 \\
\hline 9 & C.A & Props & 166,50 & 57,80 & 15,30 \\
\hline 10 & G.D & Center & 154,00 & 53,70 & 6,00 \\
\hline 11 & U.P & Wing & 165,00 & 62,30 & 9,00 \\
\hline 12 & M.M & Center & 158,00 & 60,80 & 14,50 \\
\hline Minimum & 154 & 53,40 & 6,00 \\
\hline Maximum & 171 & 65,10 & 25,50 \\
\hline Average & & 162,4 & 57,44 & 15,89 \\
\hline \multicolumn{5}{|l|}{ Standard deviation } \\
\hline \multicolumn{2}{|l|}{ Coefficient variations (\%) } & 4,79 & 3,587 & 4,371 \\
\hline
\end{tabular}

Table 2. Results of the national lot of Ukraine

\begin{tabular}{|c|c|c|c|c|c|}
\hline No. & $\begin{array}{c}\text { Name /first } \\
\text { name }\end{array}$ & Positions & Height & $\begin{array}{c}\text { Weight } \\
\text { (kg) }\end{array}$ & $\begin{array}{c}\text { Spinal } \\
\text { mobility (cm) }\end{array}$ \\
\hline 1 & B.M & Wing & 162,00 & 57,00 & 30,60 \\
\hline 2 & C.K & Hooker & 165,50 & 65,00 & 15,50 \\
\hline 3 & P.D & Props & 170,00 & 64,00 & 20,00 \\
\hline 4 & D.V & Scrum-half & 160,50 & 56,50 & 30,50 \\
\hline 5 & B.O & Center & 172,00 & 58,00 & 31,00 \\
\hline 6 & P.O & Fly-half & 165,40 & 60,50 & 29,50 \\
\hline 7 & U.S & Center & 162,00 & 57,00 & 19,30 \\
\hline 8 & G.A & Props & 167,50 & 63,40 & 20,00 \\
\hline 9 & I.O & Hooker & 170,00 & 65,30 & 18,50 \\
\hline 10 & T.T & Wing & 172,50 & 68,00 & 28,30 \\
\hline 11 & M.T & Props & 171,00 & 65,30 & 14,00 \\
\hline 12 & U.A & Scrum-half & 160,50 & 54,70 & 21,70 \\
\hline \multicolumn{3}{|c|}{ Minimum } & 160,5 & 54,70 & 14,00 \\
\hline \multicolumn{3}{|c|}{ Maximum } & 172,5 & 68,00 & 31,00 \\
\hline \multicolumn{3}{|c|}{ Average } & 166,6 & 61,23 & 23,24 \\
\hline \multicolumn{3}{|c|}{ Standard deviation } & 4,539 & 4,445 & 6,314 \\
\hline \multicolumn{3}{|c|}{ Coefficient variations (\%) } & 2,72 & 7,26 & 27,17 \\
\hline
\end{tabular}


It has been shown most of the time that rugby is a sport dominated by skill, speed and endurance. Qualities found in most players tested, the waist line in rugby in 7 representing a "bonus" that eases the effort made in certain procedures specific to this game.

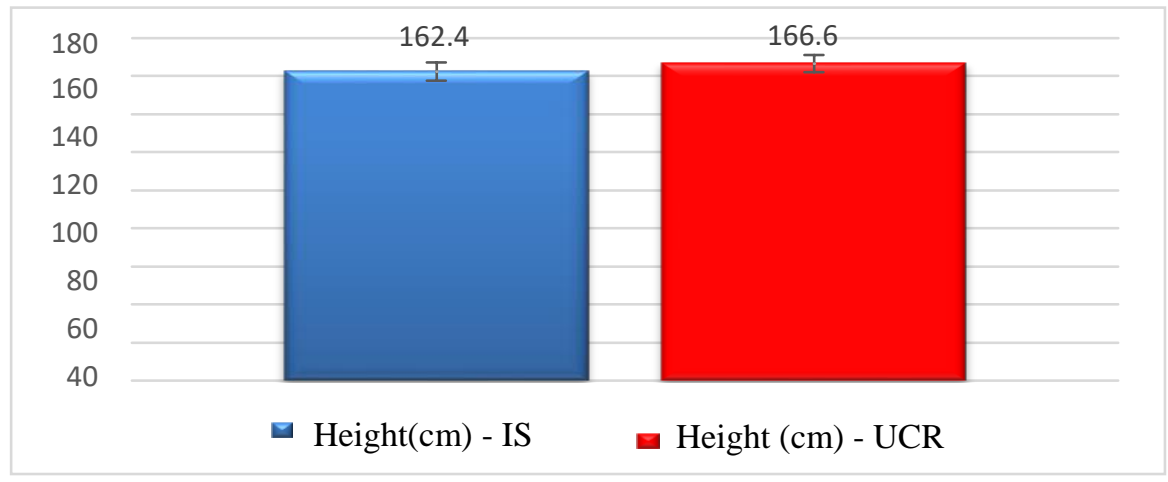

Fig. 1. The height of the players of lot $A$ and $B$

Players belonging to lot $\mathrm{B}$ have an average of $4 \mathrm{~cm}$ higher than the players in lot A (Figure 1).

The standard deviation in this case being a significant one $\mathrm{P}<0,05$ (Table 1 and 2).
Even if the result of the averages of the two lots the height of the players is significant, in rugby the strength of the arms, the ability of the player to maneuver the ball and make decisions quickly are the qualities that make their mark the most.

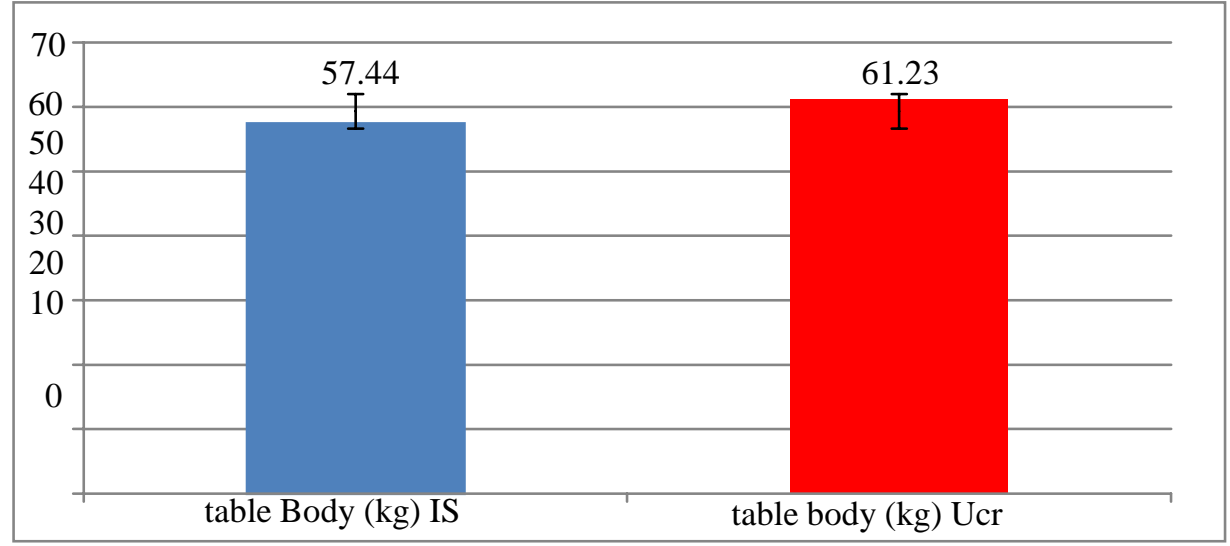

Fig. 2. Body mass (kg) of a lot A and B

The average weight between the two compartments (forward and backs compartment), is quite close, it is quite difficult to distinguish a player belonging to the forward compartment, from a player belongs to the backs line. This is because with the transition of rugby in 7 as an Olympic sport, performance standards have increased, with the game becoming much faster and well structured, which also brings major changes in terms of the morphological profile of the player.

Results on the weight of the players (Figure 2) also have a significant value of 
$\mathrm{P}<0,05$. Players of lot $\mathrm{A}$ recording an average weight of 57.44 and $61.23 \mathrm{~kg}$ respectively for players in lot $\mathrm{B}$, the difference being about 4 $\mathrm{kg}$.
The weight of the players relates to their height, so that both the players in Lot $\mathrm{A}$ and those in Lot B have an optimal weight in relation to their average height.

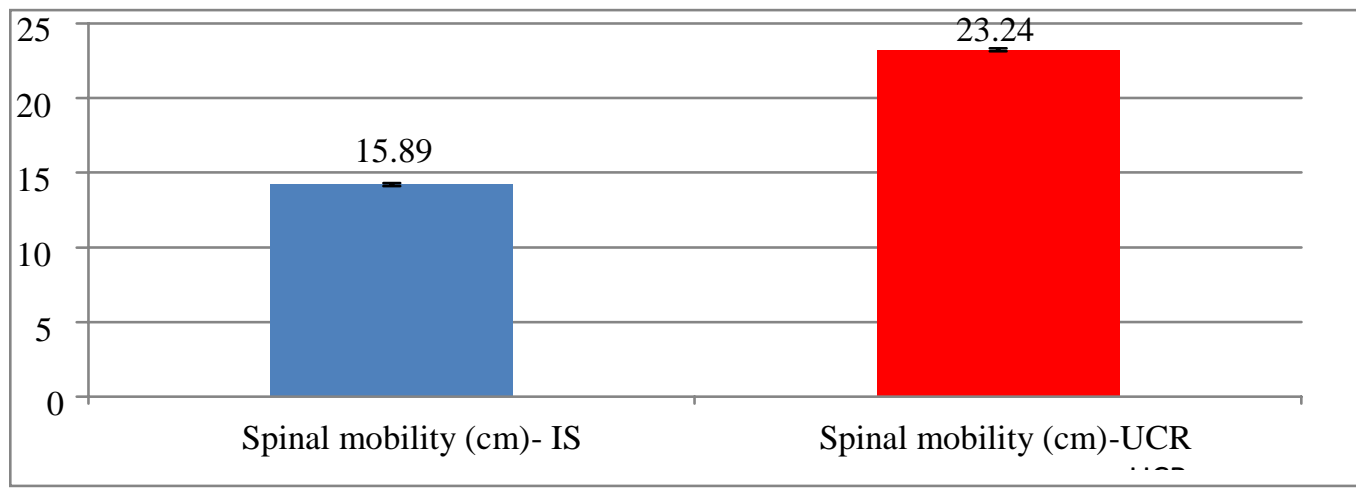

Fig. 3. Mobility of the spine (cm) of players in lot A and B

Joint mobility and muscle flexibility are of major importance to any person, especially when it comes to athletes. Good mobility allows players to achieve large, precise and fast movements, very important factors in the game of rugby.
Based on the statistical data obtained, the difference between the two batch averages is significant, as $\mathrm{P}<0,05$.

Players of lot $\mathrm{B}$ have much greater mobility compared to those of lot A.

Table 3. Test results of the SC Politehnica Iasi

\begin{tabular}{|c|c|c|c|c|c|}
\hline No. & $\begin{array}{c}\text { Name/ } \\
\text { first name }\end{array}$ & Positions & $\begin{array}{c}\text { Body } \\
\text { mass } \\
(\mathbf{K g} / \mathbf{m} 2)\end{array}$ & $\begin{array}{c}\text { Adipose } \\
\text { tissue } \\
\text { muscular }\end{array}$ & $\begin{array}{c}\text { Muscle } \\
\text { mass }\end{array}$ \\
\hline 1 & A.A. & Wing & 21,60 & 25,30 & 33,70 \\
\hline 2 & G.G & Hooker & 18,84 & 18,40 & 32,20 \\
\hline 3 & J.L & Props & 23,34 & 32,50 & 29,30 \\
\hline 4 & L.G & Scrum-half & 21,00 & 26,00 & 31,80 \\
\hline 5 & N.A & Center & 19,61 & 25,00 & 31,10 \\
\hline 6 & B.G & Fly-half & 21,59 & 30,70 & 29,00 \\
\hline 7 & S.A & Center & 22,38 & 31,50 & 28,90 \\
\hline 8 & R.S & Scrum-half & 22,59 & 30,20 & 30,20 \\
\hline 9 & C.A & Props & 20,85 & 27,20 & 30,90 \\
\hline 10 & G.D & Center & 22,64 & 25,40 & 33,00 \\
\hline 11 & U.P & Wing & 22,88 & 27,70 & 30,80 \\
\hline 12 & M.M & Center & 24,36 & 30,00 & 31,50 \\
\hline \multicolumn{2}{|l|}{ Minimum } & 18,84 & 18.40 & 28,9 \\
\hline \multicolumn{2}{|l|}{ Maximum } & 24,36 & 32.50 & 33,7 \\
\hline \multicolumn{2}{|l|}{ Average } & 21,81 & 27,49 & 31,03 \\
\hline \multicolumn{2}{l}{ Standard deviation } & 1,565 & 3,878 & 1,526 \\
\hline
\end{tabular}


Table 4. Results of the national lot of Ukraine

\begin{tabular}{|c|c|c|c|c|c|}
\hline No. & $\begin{array}{c}\text { Name/ } \\
\text { first name }\end{array}$ & Positions & $\begin{array}{c}\text { Body } \\
\text { mass } \\
\text { (kg/m2) }\end{array}$ & $\begin{array}{c}\text { Adipose } \\
\text { tissue } \\
\text { muscular }\end{array}$ & $\begin{array}{c}\text { Muscle } \\
\text { mass }\end{array}$ \\
\hline 1 & B.M & Wing & 22,40 & 19,00 & 34,40 \\
\hline 2 & C.K & Hooker & 19,00 & 21,50 & 32,70 \\
\hline 3 & P.D & Props & 20,50 & 23,10 & 30,20 \\
\hline 4 & D.V & Scrum-half & 21,00 & 25,70 & 31,40 \\
\hline 5 & B.O & Center & 22,50 & 21,00 & 34,20 \\
\hline 6 & P.O & Fly-half & 21,00 & 24,56 & 35,19 \\
\hline 7 & U.S & Center & 20,45 & 19,89 & 28,90 \\
\hline 8 & G.A & Props & 19,00 & 20,30 & 29,40 \\
\hline 9 & I.O & Hooker & 18,32 & 18,40 & 30,50 \\
\hline 10 & T.T & Wing & 21,58 & 22,00 & 30,42 \\
\hline 11 & M.T & Props & 20,40 & 23,50 & 31,70 \\
\hline 12 & U.A & Scrum-half & 21,81 & 20,32 & 30,64 \\
\hline Minimum & & 18,32 & 18.40 & 28,9 \\
\hline Maximum & & 22.50 & 25.70 & 35,19 \\
\hline Average & & 20,66 & 21,61 & 31,64 \\
\hline \multicolumn{2}{|l|}{ Standard deviation } & 6,346 & 2,24 & 2,053 \\
\hline \multicolumn{2}{l}{ Coefficient variations (\%) } & 10,37 & 6,49 \\
\hline
\end{tabular}

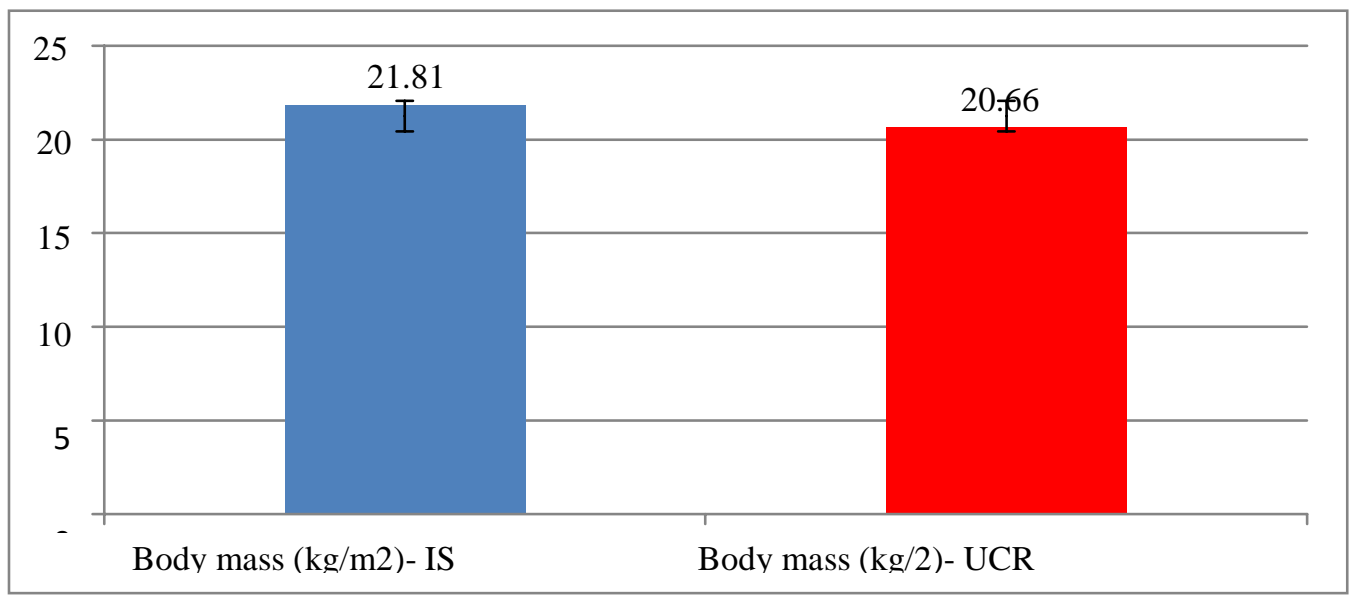

Fig. 4. Body mass (kg/m2) of players in lot A and B

Muscles weigh more compared to fat deposits, so body mass index will be higher in the case of an athletic body. For example, rugby players have a body mass index that indicates the state of obesity, even if they do not have excess body fat.
As regards the averages of the two groups in terms of body mass index, the difference is not significant, the values being close, ranging from $1.14 \pm 0.59$.

The coefficient of variability being 7,10\% in the SC Politehnica Iasi lot and in the Ukrainian lot being 6,52\%. 


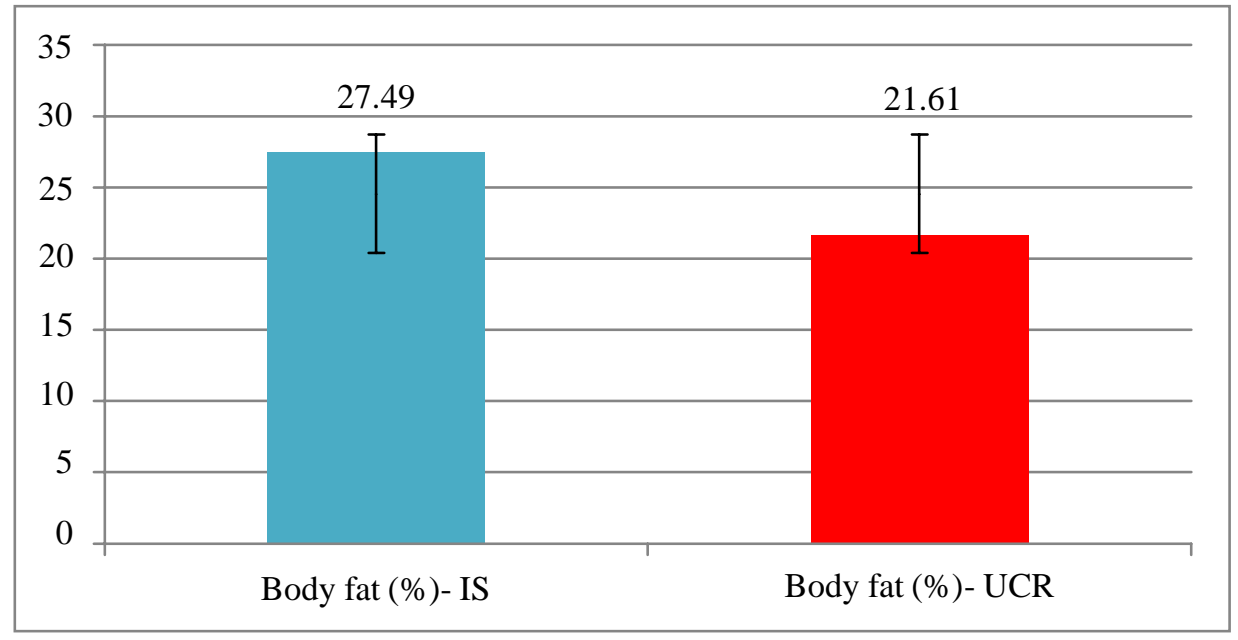

Fig. 5. Mass of muscle fat (\%) lot A and B

Rugby is a sport in which the predominant effort is aerobic and strength is an important component in almost all phases of the game.

Studies have shown that an increased mass of adipose tissue decreases the performance of the athlete.
In our case, the percentage of adipose tissue is considerably higher for players in Lot A (Figure 5), the difference between the averages of the two groups being a significant one $5.88 \pm 1.29$ (Table 3 and 4).

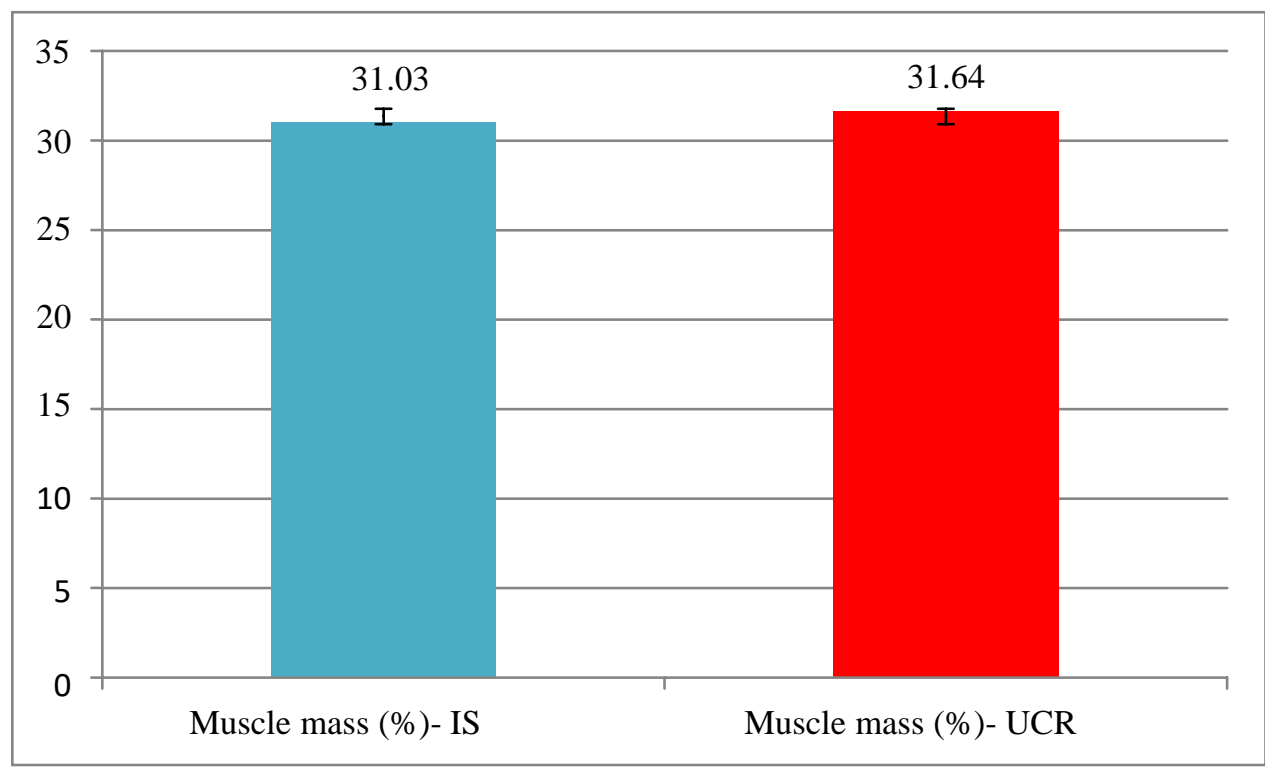

Fig. 6. Percentage of muscle mass of the two lots

Following the analysis carried out on the two lots, the results are similar, the difference being insignificant both in terms of the mean of the two lots (Figure 6) and in terms of standard deviation (Table 3 and 4 ).
In order to form a clear picture of the morphological differences between the two groups, we have below represented the differences between the profile of the players by compartment. 


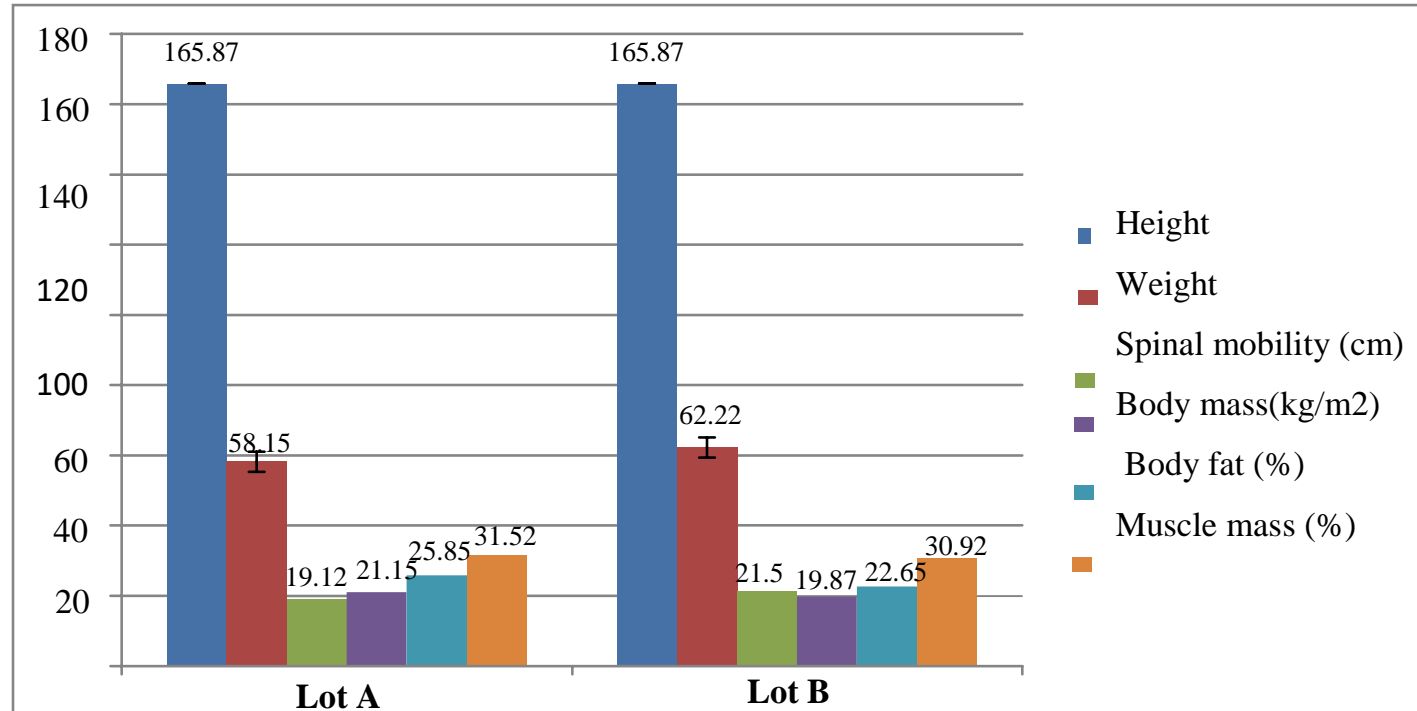

Fig. 7. Average of the results of the forward compartment of lot $A$ and $B$

The forward compartment is characterized by force, the fixed phases of the match such as the ordered scrum, the ruck or the edge, highlight the use mainly of isometric contractions which require the musculature to a greater percentage.

If the average of the tests carried out over the whole team showed that there are significant differences between the two groups, especially in the level of muscle mass, mobility and fat tissue, the tests carried out at the compartment level show a better weight of the players of lot $\mathrm{A}$.

Following the results shown in Figure 7, the two forward compartments have close values. Significant differences being detected in the level of weight, mobility of the spine and adipose tissue.

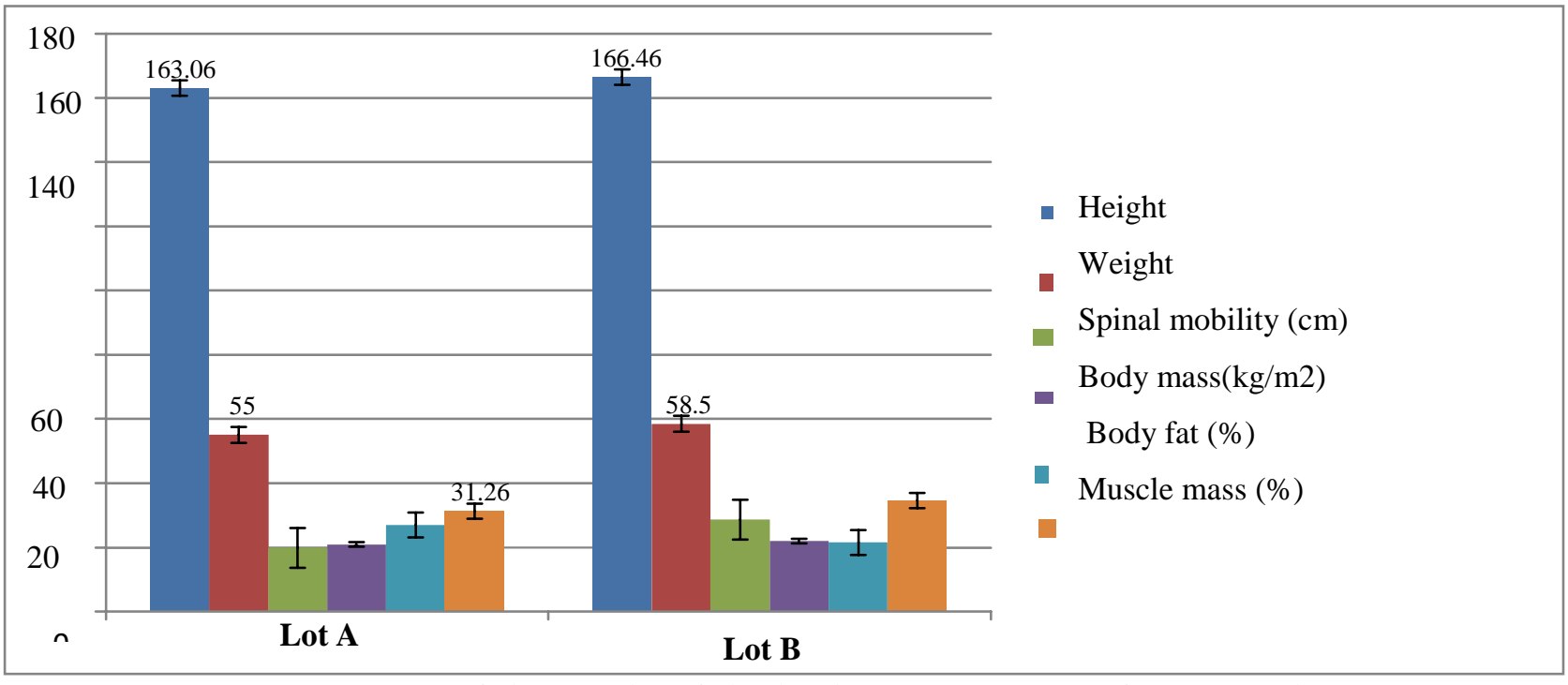

Fig. 8. Average of the results of the backs compartment of Lot $A$ and $B$ 
The backs compartment is characterized by speed. The phases deployed at this level are very demanding, the effort put in during the 14 minutes of the game being a maximum one. Players must placate the opponent, get up, retrieve the ball, pass it or shoot it, all of these phases of the game executed at speed.

Following the analysis carried out on the two compartments, the players of lot B have a much better physical condition compared to the players of lot $\mathrm{B}$.

Both at the level of muscle mass, body of fat and mobility, the players of lot $\mathrm{B}$ beind over the players of lot A.

\section{Conclusions}

Following the analysis of the statisticalmathematical results of the two groups, the body composition of the players in lot $\mathrm{B}$ is slightly above the average of the players in lot
A. So the only significant differences are discovered from the analysis of the results of the fat trest mass and the mobility of the spine.

Body size values vary according to anthropometric indices, but the values recorded by the players of lot $\mathrm{A}$ are close to optimal.

The results of the analysis on compartments help to confirm the hypothesis, since following the study started, the players of the forward compartment fall between the optimal values of the players of lot $B$, the backs compartment recording values close to the optimal ones (the values of the national team of Ukraine).

Since the Ukrainian national team operates in the first European value echelon, the C.S. Politechnica Iasi team falls between the optimal parameters.

\section{References:}

1. Agar-Newman D.J., Goodale T., Klimstra M. (2017). Anthropometric and Physical Qualities of International Level Female Rugby Sevens Athletes Based on Playing Position. In: Journal of Strength \& Conditioning Research, 31(5), p. 1346-1352.

2. Barkell J. F., O'Connor D., Cotton W. G. (2017). Characteristics of winning men's and women's seven rugby teams throughout the knockout Cup stages of international tournaments. In: International Journal of Performance Analysis in Sport, 16, p. 633-651.

3. Carreras D., Kraak W., Planas A., Martin I., Vaz L. (2013). Analiza meciurilor internaționale de rugby din timpul turneelor. In: International Journal of Performance Analysis in Sport, 13, p. 833-847.

4. Duthie G., Pyne D., Hooper S. (2003). Applied physiology and game analysis of rugby union. In: Sports Medicine, 33, p.973-991.

5. Fleck S.J. (1983). Body composition of elite American athletes. In: The American Journal of Sport Medicine, 11, p. 398-403.

6. Higham D.G., Pyne D.B., Anson J.M., Eddy A. (2012). Movement patterns in rugby sevens: Effects of tournament level, fatigue and substitute players. In: Journal of Science and Medicine, 15, p. 277-282.

7. Higham D.G., Pyne D.B., Anson J.M., Eddy A. (2013). Physiological, antropometric and performance characteristics of rugby sevens players. In: International Journal of Sports Physiology and Performance, 8, p. 19-27.

8. Ohya T, Asami K, Miyazaki Y, Iwai Y, Hirai H, Ikeda T. (2015). Anthropometric and Physiological Characteristics of the Japanese Elite Women's Rugby Sevens Players. In: Football Science, vol. 12, p. 84-90.

9. Suarez-Arrones L, Nunez F, Portillo J, Mendez-Villanueva A. (2012). Match running performance and exercise intensity in elite female Rugby Sevens. In: Journal of Strength \& Conditioning Research, 26(7), p. 1858-1862. 